\title{
Waste disposal, introduction of waste reform and environmental tax in Russia
}

\author{
Galina Semenova ${ }^{1}$, $^{*}$ \\ ${ }^{1}$ Plekhanov Russian University of Economics, Stremyanny per., 36, Moscow, Russia \\ ${ }^{2}$ Moscow Region State University, 105005, Radio str, 10A, Moscow, Russia
}

\begin{abstract}
Due to the fact that the country's population is growing, the demand for consumer resources is also increasing. As a result of an increase in resource consumption, the amount of municipal waste is also increasing. It is a logical fact that without the timely introduction of innovative technologies for waste recycling, the planet will soon turn into a huge dump and become unsuitable for the existence of not only people but all living creatures. In order to avoid such a result, scientists from many countries have long been looking for optimal ways to deal with waste, thanks to which it would be possible to eliminate or recycle municipal solid waste (MSW) without harming the environment, as well as rid the territorial space of huge amounts of garbage. The subject of the study is the methods of MSW disposal. The purpose of the study is to regulate the management of waste, which occupies an increasingly large area. Water bodies are polluted due to wastewater and carry many infections and elements dangerous to nature. Methodology. To study the topic, the main indicators are systematized: the volume of waste generation by type of activity and hazard class over 20 years. Comparative, economic and statistical methods of analysis were used for substantiating the findings. Results. Disposal of municipal waste should be developed no less than manufacturing industry, so that the generated municipal solid waste could not accumulate and pollute the soil, atmosphere and water.
\end{abstract}

\section{Introduction}

Many countries have long been looking for optimal ways to deal with waste, thanks to which it would be possible to eliminate or recycle MSW without harming the environment, as well as rid the territorial space of huge amounts of garbage. Nowadays, the disposal of municipal solid waste is carried out by the following methods that allow getting rid of garbage:

- burial or temporary storage of waste at special landfills where sorting is carried out, and unsuitable materials is covered with earth.

- composting - a method of natural decomposition of biological substances, their processing into mineral fertilizers for soil and planting crops.

\footnotetext{
* Corresponding author: Sg6457@mail.ru
} 
- heat treatment - a method of burning almost any type of garbage, which minimizes their volume as much as possible, and also gives economic benefits in the form of thermal energy.

- low temperature and high temperature pyrolysis.

MSW burial. Disposal of solid waste by burial at landfill is one of the most common ways today to get rid of garbage. But this method is common only among non-combustible waste, as well as among those substances that can emit toxic elements during combustion.

A landfill for MSW burial is an unusual landfill, it is equipped with all modern engineering facilities that allow systems for combating soil and groundwater pollution to isolate all harmful substances. This also applies to the atmosphere, which is the main goal to ensure the safety of the country's ecology.

But there are also shortcomings in such methods, for example, the formation of gas in the process of decay of garbage. Some landfills for municipal solid waste are equipped with special equipment for pumping gas, which is subsequently used to generate electricity, and allows the equipment located at landfills to operate almost autonomously. But, unfortunately, so far, only a small part of all such landfills in Russia are equipped with such equipment, while all other waste disposal sites are not able to deal with gas emissions.

But even taking into account the presence of such plants, the environment remains unprotected from the effect of decomposition of garbage in the soil and from all the emissions in the process of decay and fermentation, since the buried material will completely disappear only after tens or even hundreds of years. Therefore, despite the relative cheapness of this method of dealing with garbage, the best option for ecology is to completely get rid of garbage by recycling it and using it in the manufacture of any product. In case of a waste burial, the risk of environmental pollution is minimized.

Composting MSW. Utilization of municipal waste by composting is a technology that allows disposal of food waste and solid waste through natural biodegradation. The main source of composting is organic substances and materials. This method is used to them very actively. Composting not only gives the opportunity to get rid of bulk substances that pollute the environment, but also provides agriculture with fertilizers that are useful for the soil, which help to normalize the balance of minerals in the earth and grow various vegetables and crops.

But since this method does not allow recycling most types of garbage, requires a careful sorting process and takes a lot of time, it has not gained popularity in the country and is not developed at the proper level. In Russia, there is not a single industrial enterprise that composted in such volumes and made it possible to clean at least one city of organic waste. This method is often used only for individual purposes: in small farms; on garden plots; in private homes; in agricultural organizations; at livestock farms, etc.

However, this method does not require large expenditures, although it does not cover all types and classes of waste material, but it allows fully getting rid of the huge part of the waste produced by the country, which occupies a third of all the country's waste. It is necessary to establish a centralized process and compost at special sites equipped with all the necessary facilities. For this, it is necessary to build original plants, firstly in large cities of the country, for the processing of MSW and other organic waste. The final product, compost, will be very useful in many agricultural enterprises, and, most importantly, its cost price will reduce the cost of growing many crops and provide funds for the operation of such plants.

Thermal processing of MSW. Using heat treatment, the disposal of municipal waste allows getting rid of organic fractions. This method is often used in large-scale volumes of garbage formation. Thermal processing of municipal waste is a few processes that together allow getting rid of any non-toxic type of waste material or minimizing them in volume and mass. 
With all the various methods of disposal or elimination of MSW, the method of incineration can be considered the most waste-free, since it eliminates materials and substances of any volume and turns them into ash, which is hundred times takes up less space and does not have the ability to rot and to release harmful gases to the atmosphere. Also, ash cannot be toxic, it is not afraid of temperature changes, it does not require specially equipped landfills for burial.

Waste incineration plants or organizations receive thermal energy or electricity, which can be used for the autonomous operation of the enterprise. In some cases, surplus of such energy is redirected to city stations, which ultimately allows providing whole areas with electricity or heating them.

Plasma processing of MSW. This method is not as developed as the above methods and ways of waste disposal, but it is a very promising technological process that allows solving all environmental problems, disposing municipal solid waste, and ultimately providing energy that is useful and necessary for society. The technological process of plasma processing uses a melting temperature that is much higher than in any slag melting furnace. Thus, the output is a glazed product that is completely harmless and, most importantly, does not require further costs for detoxification or special disposal. Plasma processing is a garbage gasification technology, a scheme of this method allows getting gas from the biological components of the waste. The resulting gas is subsequently used to generate electricity or steam. The main material for plasma processing is solid waste in the form of slag or neutralizable residues.

\section{Figures and tables}

The area of Russia is $1,700,075,400$ ha. It will take 7,000 years to cover the entire territory with garbage. Industrial facilities are the main source of waste generation - $91 \%$ of the total mass is generated by mining, $4.3 \%$ of garbage is the result of metallurgical activities, $1.5 \%$ of waste is generated by energy companies, $0.6 \%$ is chemical production. Municipal solid waste occupies $2.3 \%$ of all landfills [1].

The method of waste processing - incineration, is currently used in many countries. So, the volume of incineration of municipal waste in the UK and the US is $10 \%$; in Austria, Italy, France, Germany - from 20 to $40 \%$; in Belgium, Sweden - 48-50\%, in Japan - 70\%, in Denmark, Switzerland - $80 \%$. In our country, only about $2 \%$ of MSW are currently incinerated, and in Moscow - about 10\%.

Solving the problems of recycling industrial wastes and preventing their negative impact on the environment is a priority for Russia. Nowadays, more than 94 billion tons of solid waste has accumulated in dumps and storages on the territory of Russia. According to official data, more than 3.5 billion tons of waste is generated annually in Russia, including 35-40 million tons of municipal solid waste (MSW) (Fig. 1). 


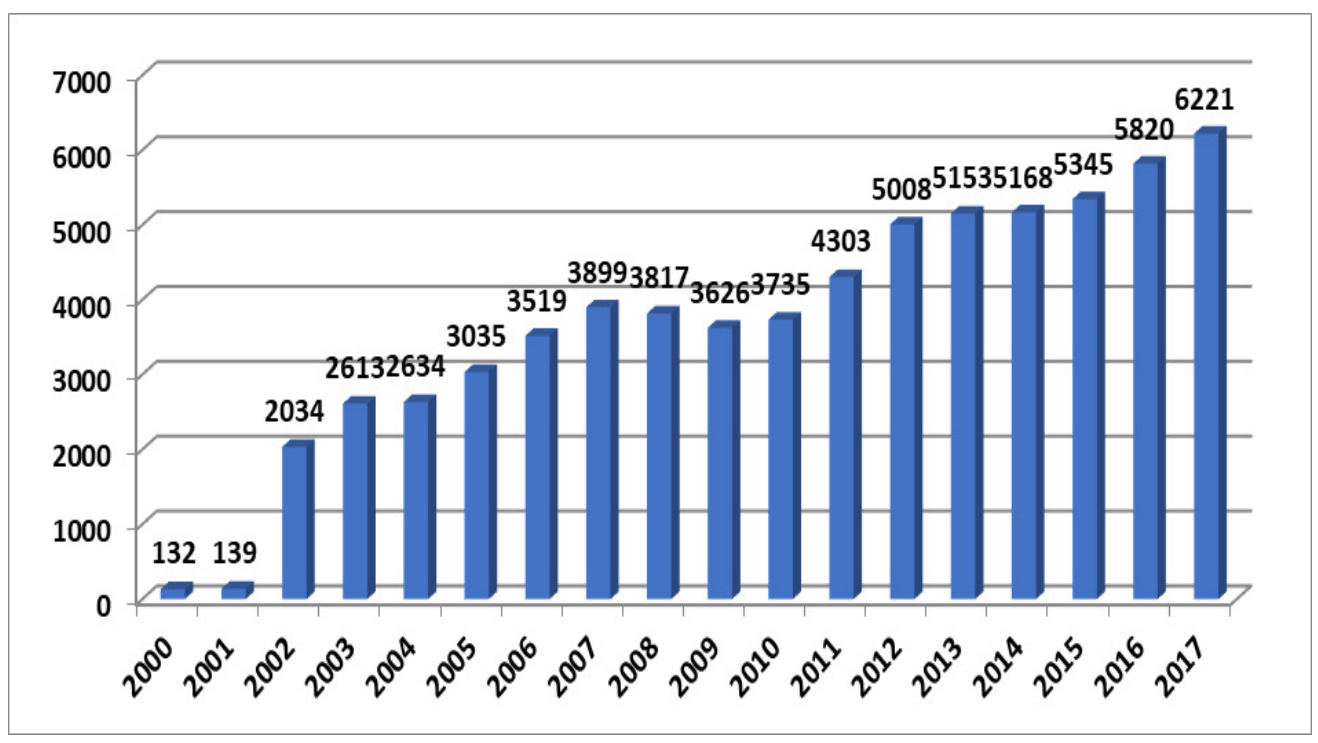

Fig. 1. Waste generation in Russia, million tons

Between 2010 and 2017, the amount of waste generated annually increased from 3,735 million tons to 6,221 million tons, or $66.5 \%$. The volume of waste generation, including by type of activity and hazard class, is shown in Table 1.

Table 1. The volume of waste generation by type of activity and hazard class

\begin{tabular}{|l|c|c|c|c|c|c|c|c|c|c|}
\hline $\begin{array}{c}\text { Volume of waste } \\
\text { million tons }\end{array}$ & $\mathbf{2 0 0 7}$ & $\mathbf{2 0 1 0}$ & $\mathbf{2 0 1 1}$ & $\mathbf{2 0 1 2}$ & $\mathbf{2 0 1 3}$ & $\mathbf{2 0 1 4}$ & $\mathbf{2 0 1 5}$ & $\mathbf{2 0 1 6}$ & $\mathbf{2 0 1 7}$ \\
\hline $\begin{array}{l}\text { Total volume of waste } \\
\text { generation } \\
\text { here: }\end{array}$ & $\mathbf{3 8 9 9}$ & $\mathbf{3 7 3 5}$ & $\mathbf{4 3 0 3}$ & $\mathbf{5 0 0 8}$ & $\mathbf{5 1 5 3}$ & $\mathbf{5 1 6 8}$ & $\mathbf{5 3 4 5}$ & $\mathbf{5 8 2 0}$ & $\mathbf{6 2 2 1}$ \\
\hline $\begin{array}{l}\text { agriculture, forestry and } \\
\text { fishing }\end{array}$ & 27 & 24 & 28 & 26 & 40 & 43 & 45 & 51 & 53 \\
\hline mining & 2785 & 3335 & 3819 & 4629 & 4701 & 4807 & 4912 & 5332 & 5675 \\
\hline manufacturing industries & 243 & 280 & 280 & 291 & 254 & 243 & 280 & 310 & 350 \\
\hline construction & 63 & 11 & 14 & 15 & 17 & 18 & 20 & 22 & 25 \\
\hline $\begin{array}{l}\text { production and distribution of } \\
\text { electricity, gas and water }\end{array}$ & 71 & 68 & 57 & 28 & 24 & 28 & 30 & 45 & 55 \\
\hline $\begin{array}{l}\text { other types of economic } \\
\text { activity }\end{array}$ & 710 & 17 & 105 & 19 & 117 & 29 & 58 & 60 & 63 \\
\hline $\begin{array}{l}\text { The total volume of } \\
\text { hazardous waste generation } \\
\text { (I-IV hazard class) per unit of }\end{array}$ & 7.412 & 2.470 & 2.147 & 1.827 & 1.748 & 1.741 & 1.785 & 1.950 & 2.105 \\
$\begin{array}{l}\text { GDP at current prices } \\
\text { (t/million rubles) }\end{array}$ & & & & & & & & \\
\hline
\end{tabular}

Today, more than half of the waste (54\%) is generated during the extraction of fuel and energy minerals (mainly the coal industry), $17 \%$ falls to non-ferrous metallurgy, $17 \%$ - to ferrous metallurgy, and $12 \%$ to other waste, including municipal (Fig. 2) 


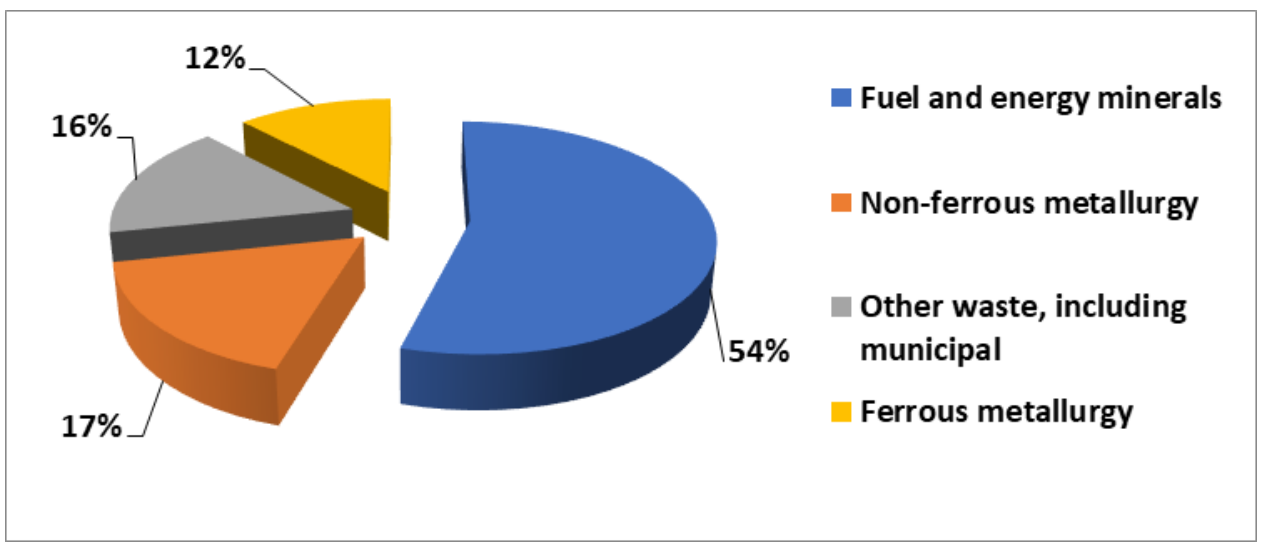

Fig. 2. Waste generation by industry in Russia

The landfill area in Russia is 4 million hectares - this is the area that is used for landfills in the territory. This figure is quite comparable with the size of some countries, for example, Switzerland (4.12 million hectares) or the Netherlands (4.15 million hectares). The area of Slovenia ( 2 million ha) and Israel ( 2.2 million ha) is 2 times less than the landfills of our country [2].

The growth dynamics of landfills is surprising - every year, the figure increases by the size of the territory of Moscow in its new borders. Moscow authorities are taking steps to dispose of industrial and municipal waste [3]. Every year, 8-10 million tons of garbage are sent to the territory of the Moscow region. 600 kilograms of municipal waste are accounted for every inhabitant of the capital. There are 39 official landfills on the territory of the Moscow region. Twenty four facilities no longer accept garbage due to the completion of the license. Landfill sites that continue to operate also take on the entire volume with difficulty.

There is almost no waste processing industry in Russia. This factor is a very negative point, because large and small cities are quite heavily littered. Officially, 1,000 landfills and 15,000 official disposal sites are registered in Russia, 17,000 landfills are unauthorized (Fig. 3).

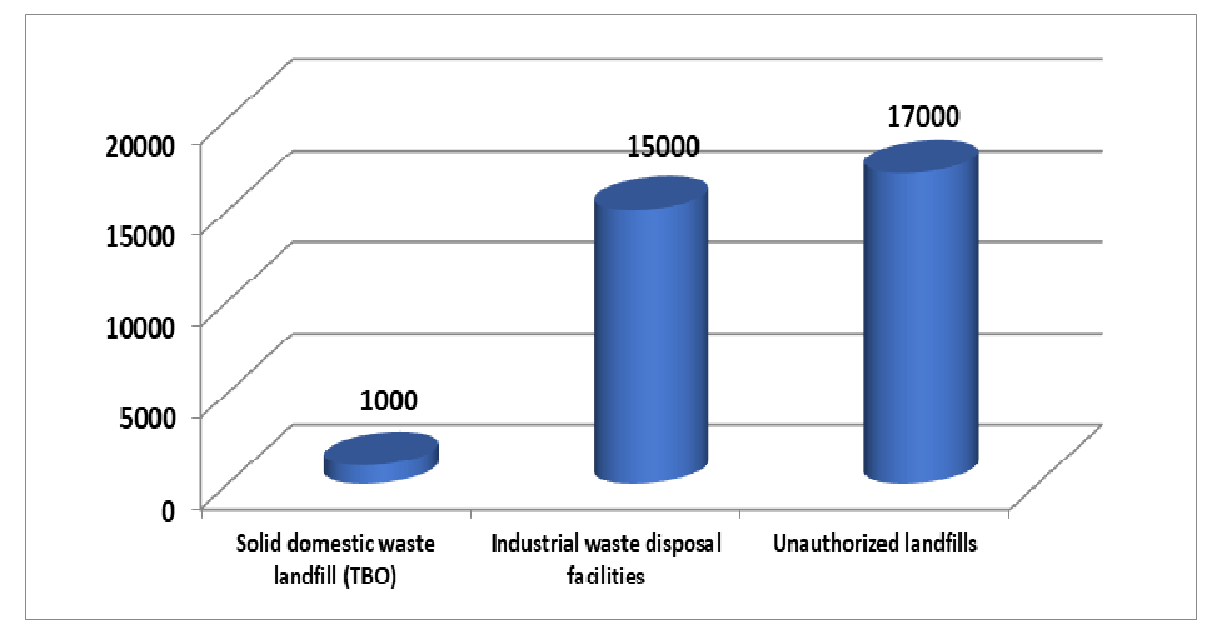

Fig. 3. Waste disposal facilities in Russia 
And what about the situation in other countries? For example, in the United States of America, one and a half million people are involved in the collection and disposal of garbage. 56,000 different enterprises operate in order to recycle waste. The annual turnover is $\$ 240$ billion. There are 550 garbage processing plants in the country.

German authorities combating garbage differently by introducing a waste disposal fee. Manufacturers are also required to pay attention to product packaging. It should be re-used or completely decomposed. In Germany, a plant was built and tested by the Technical Control and Supervision Service (TÜV), which has been successfully operating on this technology in test mode for ten years. Germany is a pioneer in waste management in the world. Every year, the country processes raw materials worth half a trillion euros, and the proportion of recycled waste reaches $65 \%$ [4].

In Finland, gas is emitted from garbage. Waste is laid on the landfill in layers, and then cover them with the film under which it is collected. Gas is collected and energy is received, thereby benefiting from landfills.

In Russia, new polygons will appear in five points of the Moscow region: SerebryanoPrudsky, Sergiev-Posadsky, Orekhovo-Zuevsky, Kashirsky and Voskresensky. These sites are located mainly in the eastern and southeastern part of the Moscow region, the most densely populated and with a lack of infrastructure. Modern waste recycling plants will be located at all new landfills [5].

Thermal neutralization of municipal solid waste at high temperature provides a better environmental effect than the placement of waste in landfills. Therefore, it was decided to build four such plants in the Moscow region - in the area of Naro-Fominsk, Solnechnogorsk, Noginsk and Voskresensk - with a capacity of 700 thousand tons each. Half of the capacity of the plants will be reserved for the thermal neutralization of municipal solid waste coming from Moscow. The wording "thermal treatment plants" combines all currently existing technologies for the disposal of waste: gasification, burning, pyrolysis, plasma method.

\section{Results}

The problem of environmental protection is complex and global in nature. Therefore, since January 2019, a new system of municipal solid waste management has been launched in Russia. A single regional operator has appeared in each region, who is responsible for garbage collection from the moment of loading to placement on the landfill. Garbage itself must be pre-sorted before entering a specialized landfill.

In addition to the new waste management system, a Unified state accounting and control system has been developed. This is an online map of the movement and disposal of hazardous waste. Previously, management companies themselves hired organizations that took out garbage to landfills. Now all responsibility for the industry falls on the shoulders of the regions. They choose the operator, decide where to build waste recycling plants, how to motivate the population to collect garbage separately.

The garbage collection fee itself was included in the list of housing services, and it became communal from January 1, 2019. The mechanism for charging garbage collection has also changed. If earlier it was calculated based on the area of the apartment, then from January 1, 2019, it depends on the number of residents, with the exception of the Moscow region, where the calculation for solid waste is done according to the old one - based on the area of the apartment. All citizens pay for the new service, including those who live in private residential buildings and in horticultural partnerships. In addition, the regions themselves are divided into zones in which different tariffs may apply. It is calculated as follows: in each subject, the standard for the accumulation of garbage per person is 
established, the rates of the regional operator are approved. Then these numbers are multiplied and divided by two.

Garbage reform leads to a serious increase in utility bills. Besides, there are additional costs - preliminary sorting of garbage, special vehicles that will remove this waste, the construction of waste recycling plants. Operators shift all this functions to the shoulders of consumers. Prices are increasing, somewhere the tariff will double; somewhere, it can grow 15 times.

From January 1, 2020, legal entities and individual entrepreneurs will have to pay an environmental tax. The main goal of introducing new penalties is to improve the environmental situation, reduce polluting emissions and discharges into the environment. The introduction of this tax will be an excellent incentive for enterprises to introduce technologies aimed at reducing environmental damage in the process of their activities. This will help reducing the amount of tax, which means it has financial benefits [6].

The following will be taxed: emissions entering the atmosphere during the production process; discharges that pollute rivers and water bodies; sewage water and other pollutants; waste generated as a result of mining or processing production. In general, the environmental tax will replace the old fees for emissions and discharge, but it is planned to improve the payment mechanism. In addition, a penalty will be provided for non-payment, so it will be unprofitable for entrepreneurs and enterprises to evade tax. Only those enterprises will be exempted from tax collection, in the activities of which exclusively municipal solid waste is generated [6]. Environmental tax payment mechanisms still require serious refinement and improvement. The fact is that channels have not yet been provided through which money from the state will go to recycling plants. This is only one of the nuances, and there are quite a lot of them, so the bill requires not only consideration, but also refinement. If the environmental tax (ET) will be finally introduced in 2020, its size will be calculated according to a certain formula. The amount of payment will depend on the following factors: the volume and mass of emissions, discharges or waste; their toxicity and environmental hazard; established standards and other factors. The final amount to be paid will be calculated using the following formula:

$\mathrm{ET}=\mathrm{R} \times \mathrm{M} \times \mathrm{N}: 1000$,

where,

$\mathrm{R}$ - the rate of environmental fees, presented in ruble currency per ton of emissions, it is approved at the federal level;

$\mathrm{M}$ - the mass of the product that was released to the market, the same applies to its packaging material, the indicator is expressed in kilograms;

$\mathrm{N}$ - the norm of disposal.

This formula is used by suppliers of products that have completely abandoned selfprocessing of waste. If the company is working on this aspect, but partially complied with the recycling rate in the previous year, the formula will look different:

where,

$$
\mathrm{R}=(\mathrm{AE}-\mathrm{AF}): 1000 \text {, }
$$

$\mathrm{R}$ - the rate of fee;

$\mathrm{AE}$ - the amount of established wastes that is disposed of over an annual period of time (in the normative parameter);

$\mathrm{AF}$ - the amount of waste that was sent to the further processing procedure, expressed in kilograms;

1000 is the divisor used to convert kilograms to tons.

After paying the environmental fee by the organization or submitting a report on compliance with regulatory values, it will fulfill its obligation to protect the environment from negative impact. 
Fixed rates are already provided for certain types of polluting substances, for example, ammonia - 138.8 per 1 ton; hydrogen sulfide - 686.2 rubles per 1 ton; nitrogen dioxide 138.8 rubles per 1 ton. Expenses of enterprises that pollute the environment with mercury or lead and compounds of these heavy metals can increase quite strongly [7].

For each ton of these substances, they will have to pay more than 18 thousand rubles. The general policy of introducing an environmental tax is as follows: the more dangerous a substance is for the environment, in particular for a person, the more you will have to pay for getting it into air, water or soil. For enterprises located in regions with enhanced nature protection, an additional factor will be taken into account when calculating the amount payable.

\section{Conclusions}

The methods of MSW disposal are considered and the following conclusions are made:The incineration method has many advantages over other methods, but we will highlight the main ones, these are: a high level of testing technology; stably manufactured equipment and its long service life; automated high-tech process. Important advantages of heat treatment or processing are modern methods that allow obtaining: effective decontamination or neutralization of any waste material; complete elimination of any microflora, even pathogenic one; reduction of waste in volume up to 10 times; use the energy potential of organic waste. The main advantage of high-temperature pyrolysis is the ability to environmentally dispose the waste, without unnecessary expenses: for preliminary preparation; for sorting; for drying, etc. These qualities allow thermal processing to rightfully be considered the most environmentally and economically profitable technology for the disposal of MSW.

All these methods are designed to solve the problem of waste disposal. And introduction of an environmental tax is the most effective method of internalizing environmental damage. But without the timely introduction of innovative technologies for waste recycling, the planet will soon become a huge landfill and will become unsuitable for the existence of not only people but all living beings.

\section{References}

1. Ministry of Natural Resources and Ecology of the Russian Federation, An updated annual report on the implementation and assessment of the effectiveness of the state program "Environmental Protection" for 2012-2020 for 2016 (2017)

2. United States Environmental Protection Agency. Recycling Basics (2019)

3. T.S. Meshcheryakova, IOP Conf. Series: Earth and Environmental Science 90, 012118 (2017).

4. D.A. Barabanshchikov, A.F. Serdyukova, Molodoy Uchenyy, 25, pp. 101-104 (2017)

5. E. Ganebnykh, T. Burtseva, A. Petuhova, A.Mottaeva, , E3S Web of Conferences, 91,08035, (2019) doi.org/10.1051/e3sconf /20199108035

6. G. Semenova, E3S Web of Conferences, 91, 08046 (2019)

7. G. Semenova, E3S Web of Conferences, 91, 08047 (2019) 